\title{
PSYCHOLOGICAL ANALYSIS OF SOCIOGRAM AND BIOGRAPHICAL METHOD FOR INVESTIGATING PARENTS OF CHILDREN WITH SPECIAL EDUCATIONAL NEEDS
}

\author{
BOHDANA ANDREYKO \\ Department of Special Education and Social Work \\ Ivan Franko National University of Lviv \\ 1, Universytetska St., Lviv, Ukraine \\ E-mail address: aandreykoo@gmail.com \\ ORCID: https://orcid.org/0000-0002-6303-6647 \\ IRYNA SUBASHKEVYCH \\ Department of Special Education and Social Work \\ Ivan Franko National University of Lviv \\ 1, Universytetska St., Lviv, Ukraine \\ E-mail address: irasub@ukr.net \\ ORCID: https://orcid.org/0000-0003-0453-3587
}

\begin{abstract}
Aim. In order to provide psychological counselling, it is necessary to properly diagnose and study the psycho-emotional states, psychological makers of parents raising children with special educational needs (SEN).

Methods. In the diagnostic and practical work with parents of children with SEN, we used the text analysis method and the biographical method (including projective techniques lifeline, my autobiography), which combine diagnostic and psychotherapeutic scientific results. Family sociogram technique (Eidemiller, 2002) and its modified version (Tkachova, 2014) are used to study interpersonal family relationships and the nature of communication. The article analyses the scientific data and approaches to the study of problems faced by parents, arising from the condition of their child; emotional states of parents raising a child with SEN; stage of experience of the birth of their child.

Results. Intervention is focused on the present and future. If the experience of the past comes up, it is used for the benefit of achieving certain goals. An important result of the study to be worked on is that parents of special children mention only their family and children, but forget about their own wellbeing. Children with SEN are surrounded by care and love, parents seek symbiotic relationships with children trying to satisfy all their needs, protect from difficulties, offer boundless love and sometimes over-protection.
\end{abstract}


Conclusion. Knowledge of psychological stages identified within the theory of grief helps professionals understand when and how it is better to intervene in the situation taking into account the characteristics of a particular family and individual reactions.

Key words: Biographical method, children with disabilities, emotional states, psychological counselling, special psychology

\section{INTRODUCTION}

$\mathrm{O}$ ne of the first scientific and practical tasks in the field of special psychology, special needs education and inclusion is the psychological counselling to a family raising a child with special needs, which should be aimed at creating social and psychological conditions for emotional well-being of a parent or parents of this child (Dushka, 2009). In the diagnostic and practical work with parents of children with special educational needs (SEN), we used the text analysis method and the biographical method. The biographical method (Moshkova, 1994) is a phenomenological study, which, in its turn, has the following projective techniques: lifeline and my autobiography that combine diagnostic and psychotherapeutic research results. The typology in these methods is not a type but a result.

The main tasks of psycho-corrective work with such families include (Ostrovska \& Andreyko, 2017a): helping parents overcome the trauma, familiarising them with the peculiarities of the child's upbringing and development, providing family planning counselling services, and restoring the family status of the child as a personality, which is the ultimate goal rehabilitation (Andreyko, 2016). In fact, in order to provide psychological assistance, it is necessary to properly diagnose and study the psycho-emotional states, psychological makers of parents raising children with developmental disorders, and to design on that basis the family consultations aiming at mutual understanding and the improvement of relationships in the family.

\section{RESEARCH METHODS AND PARTICIPANTS}

Family sociogram method: For studying interpersonal relationships and the nature of communication in the family, either direct or indirect, we used the method of Family sociogram developed by Edmond Eidemiller (2002a) and a modified version of this method offered by Victoria Tkachova (2014). This technique is a therapeutic tool, as it helps parents to look at the situation in the family "from above" and evaluate existing relationships. In this variant, three sheets of paper with the image of a circle are handed out, and the instruction reads as follows: "You have three circles in front of you. Each of them portrays your family at a certain stage in its life (my family before the baby is born, my family after the baby is born, my family now). In each of your circles, please draw yourself and your family members in the form of circles and letter them" 
(Tkachova, 2014, pp. 85-86). Interpretation of results by the criteria used to evaluate the test results is based on:

- the number of family members in the area of the circle and the order of their images;

- the size of the circles;

- the location of the circles relative to each other and the distance between them indicate the nature of relationships between family members.

When assessing the result using the first criterion, the number of family members depicted by the subject (the person under study) should be compared with their real number. Family members with whom this person is in a conflict may not fall into a large circle; they may be forgotten. At the same time, strangers, pets, or favourite items can be depicted as family members.

Next, the attention is paid to the size of the circles. The Self circle that is larger than the other circles says about sufficient or high self-appraisal, whereas the smaller one - about low self-appraisal. The sizes of the circles of other family members indicate their significance from the perspective of the subject.

One should pay attention to the location of the circles, within the area of the large circle, in relation to each other. If the person under study locates his/ her circle in the centre of the big circle, this might imply an egocentric personality, and the location of him/herself at the bottom, away from other circles representing family members, may indicate emotional feelings of rejection. The most significant family members are represented by large circles in the centre or at the top of the test field.

It has been found that a lot of information can be obtained by analysing distances between the circles. The remoteness of one circle from others may indicate a conflict in the family. A kind of "clumping"- when the circles are overlaying, sticking to each other, or are inside one another - indicates the undifferentiated Self in family members, the presence of symbiotic relationships.

The circles can be arranged in a linear order, indicating a formal approach to the study or the absence of a warm relationship. If the circles are freely arranged, at different distances from each other, this indicates a degree of closeness between family members. Mothers sometimes seem to attach a small circle, which means a child, to their circle, and the circle of the exhusband and father of the child may end up outside the large circle, that is, outside the family, or disappear altogether. There are also variants where the face of a family member is placed in the circle, thus the formal scheme is humanised.

The use of the Family sociogram allows visualising the relationships between family members in a matter of minutes in a "here and now" situation during a consultation or a session of family psychotherapy, by looking at the forms, discussing what came out from the test. Images of family members at the three stages of their life allow us to determine the structure of the family and those who have not withstood the difficulties associated with caring for a child. An important advantage of this technique is also the short time during which it is possible to obtain the result and form a clear view of the family. 
The generalised results of the study of the system of interpersonal relationships and the nature of communication in the family where the child with special needs is raised are received, based on the family sociogram and using the following criteria: emotional distance; emotional closeness; the presence of the father or mother in the circle after the birth of the child; the size of the circles; the presence of the direct communication in the family; the presence of a symbiotic relationship.

\section{THE RESULTS OF THE LIFELINE TECHNIQUE}

Some of the important criteria of interpretation are - "common and similar elements" as well as joint "dynamics and trend" in the picture layout. This technique allows organising the information about family history, which is difficult to compare, in a more convenient, graphical form. This technique becomes especially important when the therapist thinks about why the family is coming for help right now, and not a year earlier or later. What has changed in the family? What has become different in the external relations of the family? What has made the family seek help at this specific time? How have changes in life affected them?

The findings in a group of parents raising typical children and children with special needs can be described highlighting the essential elements that were present in most parents and drawing conclusions. The common element for everyone is a defined stage in a certain way: giving birth to a child or children, marriage or meeting a person, going to school, entering an educational institution. Certain dynamics and biographical staging can also be observed:

- a common element in the group of parents of children with special needs is a line that goes downwards after the birth of the child;

- the desire to achieve a goal, the motivation for success, for the implementation of one's plan is depicted as a line going either upwards or through obstacles: you can feel movement forward and a positive ending (flowers, trees, lights);

- the lifeline has stopped at a certain stage, there is no clear variable part or element showing that there is a future somewhere here, no positive finale is depicted;

- the lifeline is depicted as a formal drawing, hastily;

- the lifeline in the form of a ball of tangled threads, which can indicate the inability to solve many issues associated with the upbringing of a special child, possibly with a complicated diagnosis;

- a picture of the lifeline where certain elements have feelings or emotions named, such as visualisation of feelings (I felt: shock, guilt, incredible aggression, sadness, joy, happiness).

In the group of parents of children with special needs, the selected elements predominate, especially in the part of the picture which outlines the period after the diagnosis or birth of such a child, as parents try to mark it somehow, mostly negatively. 
The Lifeline technique shows that the pursuit of a goal requires the persistent overcoming of various obstacles, but the most important is the persistent striving to achieve the goal. Parents in all groups were asked to draw their own lifeline. This path (lifeline) usually demonstrates that a person goes up the stairs or other elements, and it shows some driving force towards the realisation of a plan. Interestingly, in the picture, each of the following structures, whether it is a broken line or a bar or a step, is different: some of them have obstacles and clouds, rain, or sometimes flowers. The main thing is that achieving a goal has a positive ending.

Each path looks different. In some pictures, the path looks quite unobstructed, but it requires additional factors to implement the plan. The positive end of the line is completed by fireworks, trees, sun, or flowers.

Another trend in the group of parents of children with special needs is "the way towards something," which looks like a ball of unwound and tangled threads, but despite such a complicated way, a parent either sees the optimistic end, or there is no positive end. In our opinion, this is due to the lack of a clear diagnosis or complex developmental disorders and comorbid conditions, or to the fact that the parents have no idea how to raise and care for their child. The highlighted elements, certain traits, marks, blocks after the birth of a child with special needs embody difficult experiences and non-reversible change in life.

\section{THE RESULTS OF THE MY AUTOBIOGRAPHY TECHNIQUE}

The method of My autobiography is interpreted by a researcher using the criteria for the method, as well as the text-based analysis method. The criteria are the very parts of the text, but with a biographical meaning: parts and inscribed events, the evolution of events, possible ranking of events, parts with added significance, the arrangement of events in chronological order (Ostrovska \& Andreyko, 2017b). Psychological and personality characteristics from the text-based analysis include the emotionality of events, motivation for change and a positive future, level of education that the researcher sees from the text, possible personality traits, and experiences.

The obtained results of using the My autobiography method in a group of parents who raise healthy children and children with special needs can be described highlighting the important elements that were present in most parents and that meet the basic criteria of the method, as well as drawing conclusions. It is important that parents of special children write only about family, about children, but not about their condition, or about themselves as a whole, which is a kind of selfoblivion. Our impression after working with the method is that after the birth of a child, the issue of one's emotional state and personality is blurred.

In some cases, the feelings, emotions, reasoning, and conclusions of the spent life are recorded. In the group of parents of children with special needs, they especially focus on negative experiences, lack of belief in the future, negative attitude towards everything. As for their forecast for the future, especially after the birth of a child with a developmental disability, there are more ten- 
dencies to sadness, anxiety, negativity in comparison to the group of parents of healthy children. The readability of the text was interpreted by us as a lack of motivation to change or help from a psychologist, perhaps feeling guilty about something in the future or incompetence and fear of being judged.

The projective diagnostic method Family sociogram was also used (Eidemiller, 2002) and a modified version of this method proposed by Tkachova (2014). This is a study of the system of interpersonal relationships and the possible nature of communication, emotional interconnection, and symbiosis in the family raising a child with normal development. The findings of the study based on the family sociogram are presented in percentage and according to the following criteria: emotional distance and emotional closeness, which is interpreted as an emotional relationship; the presence of a father or mother in the circle after the birth of the child; the size of the circles; the presence of a symbiotic relationship.

The results obtained in the group of parents raising healthy children can be presented in percentage as follows:

- $65 \%$ of the families in the first group have an emotional connection of parents with the child; in such families, there is a symbiotic connection, family members have no clearly differentiated Self, they are located very close to each other;

- in $15 \%$ of cases, mothers from the first experimental group have no emotional connection with their child; $10 \%$ of families, especially the father, have no emotional connection with the child;

- in $10 \%$ of families, there is no close emotional connection with certain family members, but sometimes such connections with the child are observed.

Thus, we can draw a conclusion that in $65 \%$ of families with a child with normal development, family members have an emotional relationship with each other. In $35 \%$ of families, the system of interpersonal relationships has indirect (mediated) nature of communication, possibly due to the lack of emotional connection and symbiosis between parents and child, as well as between individual family members.

The results obtained in the second group, i.e. parents of children with special needs, can be presented in percentage as follows:

- $42 \%$ of the families in the second group do not feel an emotional connection with each other, but they feel it with the child; communication in such a family can be considered mediated through the most pleasant member of the family, who is located in the picture closer to the person under study;

- $20 \%$ of families have close emotional connections with all family members, such families have a symbiotic relationship;

- in $23 \%$ of families raising a child with special needs, there are subsystems: mother-father, brother-sister, mother-daughter, father-son, mother-son, and others, which shows that parents do not feel enough emotional connection with the child and have an insufficient level of symbiotic connection, though it exists;

- in 35\% of families where a child with special needs is raised, family members feel a close emotional connection with other family members and a symbiotic relationship with the child; the communication is direct, and they are located in the picture close to each other. 
An important criterion and aspect in the study of raising a child with special needs is the presence of a father or mother in the third circle, the so-called circle: "your family after the birth of the child, today." In $32 \%$ of families in the third circle, we can observe a complete absence of the father as a family member represented here and now; in such families, according to the questionnaire, the mother does not feel supported by her husband or is raising a child on her own, i.e. this is a single-parent family.

\section{CONCLUSION}

Families with children with special needs have closer relationships and tendencies towards symbiotic relationships (circles are close to each other, or they superimpose on one another). The prospect of corrective work is focused on the present and the future. If the experience of the past follows, it is used for the sake of achieving certain goals in the future. An important result of the study to be worked on further is that parents of special children write only about their family, children, but not about their own condition or themselves in general, so a kind of self-forgetfulness is observed. The method has shown that after the birth of a child parents forget about their emotional state and their own personality. In our opinion, children with special needs are surrounded by care and love, and parents strive for symbiotic relationships with children, trying to satisfy all their needs, protect from difficulties and troubles, provide boundless love, and sometimes hyper-protection, despite the lack of emotional connection or support from the father of the child or relatives.

\section{REFERENCES}

[1] Andreyko, B. V. (2016). The emotional state of parents in the structure of the stages of the experience of having a child with developmental disabilities. Journal of Education, Culture and Society, 6(2), 150-157. doi:10.15503/jecs20162.150.157

[2] Dushka, A. L. (2009). Role of the family in the socialization of a disabled child. Science and education, 1-2, 48-52.

[3] Eidemiller, E. (2002a). Psychology and psychotherapy of a family. St. Petersburg: Peter.

[4] Eidemiller, E. (2002b). Family Sociogram Test. Retrieved March 20, 2020 from: http:// dytpsyholog.com/2015/03/24/

[5] Moshkova, B. (1994). Biographical method and the problem of personality of a scientist. Psychology Issues, 2, 131-141.

[6] Ostrovska, K. O., \& Andreyko, B. V. (2017a). Psychotherapeutic work with parents of children with special needs using short-term problem focused Brief Strategic Family Therapy (BSFT). Psychological journal. Scientific and practical journal of the G. S. Kostyuk Institute of Psychology of the NAPS of Ukraine, 1(5), 5-17.

[7] Ostrovska, K. O., \& Andreyko, B. V. (2017b). Statistical results of the effectiveness of the program of psychological services for parents of children with special needs in "peer support" groups. Psychological journal. Scientific and practical journal of the G. S. Kostyuk Institute of Psychology of the NAPS of Ukraine, 5(9), 117-128.

[8] Tkachova, V. (2014). The family of a child with disabilities: diagnostics and counselling. Moscow: National Book Centre. 